\title{
Enhancing antimicrobial stewardship by strengthening the veterinary drug regulatory framework
}

\author{
M Mehrotra ${ }^{1 *}, \mathrm{X}-\mathrm{Z} \mathrm{Li}{ }^{1}, \mathrm{MJ}$ Ireland ${ }^{1}$
}

\begin{abstract}
Antimicrobial resistance is a major and growing public health threat. Recently, Health Canada introduced multiple regulatory changes to strengthen the oversight of antimicrobial drugs for veterinary use. These changes aim specifically at increasing control over importation of veterinary drugs and active pharmaceutical ingredients, mandatory reporting of antimicrobial sales data from manufacturers, importers and compounders and facilitating access to low risk veterinary health products. Additional policy changes under existing authorities are also being made to enhance veterinary supervision of antimicrobial use and to remove production claims for food animals from labels of medically important antimicrobial drugs. These important interlinked initiatives are aimed towards enhancing antimicrobial stewardship in Canada to preserve the effectiveness of existing antimicrobials and to protect the health of Canadians.
\end{abstract}

\section{Affiliation}

${ }^{1}$ Veterinary Drugs Directorate, Health Products and Food Branch, Health Canada, Ottawa, ON

*Correspondence: manisha. mehrotra@hc-sc.gc.ca

ORCID number for XZL 0000-0003-1722-3254

Suggested citation: Mehrotra M, Li X-Z, Ireland MJ. Enhancing antimicrobial stewardship by strengthening the veterinary drug regulatory framework. Can Commun Dis Rep. 2017;43(11): 220-3.

https://doi.org/10.14745/ccdr.v43i11a02

\section{Introduction}

Antimicrobial resistance (AMR) continues to be a major public health risk that threatens the availability of effective antimicrobial therapy of infectious diseases worldwide. The development of AMR is associated with the use of antimicrobial agents in all sectors including human medicine, veterinary medicine, animal husbandry, aquaculture, plant agriculture and consumer products. As a federal authority for the regulation of antimicrobial drug products, Health Canada recognizes the human health risks associated with the emergence of AMR. Health Canada is committed to containing the development and spread of AMR while maintaining the efficacy of existing antimicrobials by promoting prudent and responsible use of these critical drugs. Health Canada's approach to evaluating and managing AMR risks associated with the use of antimicrobials in food animals is based on a complementary set of regulatory and policy initiatives. These initiatives are significant deliverables under the Government of Canada's "Antimicrobial Resistance and Use in Canada: A Federal Framework for Action" (1) and are essential elements of the stewardship component of the Pan-Canadian Framework on AMR (2). In this article, we provide an overview of the recent and ongoing initiatives being undertaken by Health Canada to strengthen the regulatory framework for veterinary antimicrobial drugs and to promote antimicrobial stewardship in veterinary medicine and the agri-food sector.

\section{Background}

Under the legal authority of the Food and Drugs Act and its Regulations, Health Canada evaluates information provided by sponsor companies concerning product quality, efficacy and animal and human safety before authorization to market a veterinary drug in Canada can be issued. The evaluation of human safety for an antimicrobial drug must include a microbiological safety assessment specific to AMR development risks. Since 2004, submission guidelines for new drug products have been made available by Health Canada to drug sponsors specifying the requirements for the human safety assessment of veterinary drugs relating to AMR (3). The safety assessment allows Health Canada to objectively analyze the AMR health risks and to determine whether current or future use of the antimicrobial drugs in animals warrants risk management actions. As a result, all new antimicrobials that are of importance to human medicine approved post-2004 have received the necessary scrutiny to limit potential unacceptable AMR risks (4). This has translated into AMR-specific warning statements on product labels, restrictions against certain uses and removal of claims that have shown to be of unacceptable risks to human health.

As Canada has a federated system of government, the provinces and territories (via the veterinarians and pharmacist professions they regulate) control the use of antimicrobial drugs, whereas the Federal Government approves the sale of these drugs. This division of responsibilities creates complexity and shared responsibility for oversight on what can be imported and sold and what can be imported and used. This has implications for proper stewardship of antimicrobial use.

Prior to the recently introduced amendments, the Food and Drug Regulations did not include appropriate oversight on importation of active pharmaceutical ingredients (APIs) of veterinary drugs. These APIs did not have to comply with the rules of Good Manufacturing Practices, and hence, did not have to meet conditions of who can import these drugs. Thus, APIs, in specific situations, could be imported and used directly in animals without further modifications. Furthermore, the 
Food and Drug Regulations did not address drug importation for use in animals by animal owners for "personal use" (also known as "own use") purposes. The existing policy in this context was established to support human health by allowing individuals to import a maximum of a 90-day supply of a drug for their own use to continue and finish medication when travelling abroad; however, interpretation of this regulation for animal use as "personal use" by animal owners created a gap. Veterinary drugs imported for personal use under the existing rules included unauthorized products of unknown quality, efficacy or safety and thus have the potential to adversely impact food safety and human and animal health.

The existence of these gaps in regulatory oversight of veterinary drugs, including antimicrobial drugs, misaligned Canada with international partners (5). This limited Canada from effectively responding to World Health Organization and World Organisation for Animal Health international recommendations on AMR (i.e., effective national controls on licensing, manufacturing, sales, distribution, monitoring and use of antimicrobials in food producing animals and the resulting impacts) $(6,7)$. This gap was also noted in a report on AMR from the Office of the Auditor General of Canada published in 2015 (8).

\section{New regulatory changes for veterinary antimicrobials}

To strengthen oversight and close the regulatory gaps in the Food and Drug Regulations, Health Canada introduced a set of amendments for consultation in July 2016 (9). As part of a multi-year effort and with effective collaboration and support from multiple stakeholders cutting across jurisdictional boundaries, Health Canada published the final regulatory changes to the Food and Drug Regulations in the Canada Gazette, Part II in May 2017 (10). These changes focused on four key measures detailed below.

\section{Increasing oversight of unapproved veterinary drugs imported for food animals}

Only drugs that Health Canada has determined not to be of risk to public health or food safety may be imported for personal use and only in limited quantities. The eligibility criteria do not allow for the importation of prescription drugs or medically important antimicrobials including active pharmaceutical ingredients.

There is the List of Certain Antimicrobial Active Pharmaceutical Ingredients (List A) that specifies individual antimicrobial drugs considered important to human medicine (11).

Another provision will ensure that no person shall import a drug into Canada for the purpose of administering it to an animal that produces food or an animal that is intended for consumption as food, unless authorized by Health Canada. This will be set out in the List of Certain Veterinary Drugs Which May be Imported But Not Sold (List B). This list will contain specific unapproved veterinary drugs that may be imported but not sold (11) and that have met all the eligibility criteria as determined by Health Canada.

\section{Increasing oversight on importation and quality of active pharmaceutical ingredients}

Under the new rules, individuals who fabricate, package, label, import or test an API for veterinary use have to do so in accordance with an Establishment License, which is issued by Health Canada to a person in Canada allowing them to conduct licensable activities in a building that has been inspected and assessed as being in compliance with relevant requirements of the Food and Drug Regulations. More specifically, all importers of an ingredient for veterinary use on List A (11), including veterinarians and pharmacists, will have to apply for an Establishment License. In addition, the new regulations will prohibit the import or sale of veterinary APIs that are not manufactured according to the Good Manufacturing Practices. This provision creates requirements around the quality of veterinary drugs on the Canadian market and that only individuals with an Establishment License are importing APIs on List $A$ and are doing so once registered with Health Canada.

\section{Requirement to file annual sales reports for medically important antimicrobials}

In contrast to the current situation, which relies upon voluntary reporting of veterinary antimicrobial sales data by drug manufacturers (via the Canadian Animal Health Institute) (12), this new mandatory data collection requirement will request manufacturers, importers and individuals who import, as well as individuals who compound medically important antimicrobials, to submit annual veterinary antimicrobial sales data to Health Canada. Data will be reported in the form of total quantity sold or compounded and an estimate of the quantity sold or compounded for each intended animal species. A data reporting template is being developed by Health Canada in collaboration with the Public Health Agency of Canada. This requirement will help measure the amount of antimicrobials available on the Canadian market for use in animals and support Canadian surveillance programs in the analysis of patterns and trends of AMR. Species-specific sales data could then be correlated with the species level AMR surveillance data, which is collected through the Canadian Integrated Program for Antimicrobial Resistance Surveillance (CIPARS) (12) and other programs. If hazards are identified from this surveillance and pursuant to a risk assessment, appropriate risk management actions would be considered in partnership with provincial regulatory bodies.

\section{An alternative regulatory pathway for veterinary health products}

Based on the premise that promoting the health and welfare of animals will help to reduce the severity and occurrence of infections and future antimicrobial usage, a flexible and risk appropriate regulatory framework for veterinary health products (VHPs) for animals has been developed to create a more streamlined approach for certain low risk health products. It provides admissible substances (such as vitamins, minerals, botanicals and traditional medicines with a history of safe use) and conditions for these products to be eligible for sale as VHPs, as identified on List of Veterinary Health Products (List C) (11).

A VHP can be sold with claims for maintaining general health and welfare of animals and cannot be marketed for the purposes of treating or preventing a disease or an infection. These low risk products are needed as an additional health management tool to reduce the need for conventional drugs (such as antimicrobials). These new rules require companies to notify Health Canada 
at least 30 days before selling a VHP or making a change to a marketed VHP. Additional requirements include labels to state "Veterinary Health Product", the reporting of serious adverse drug reactions and the manufacturing of a VHP to follow the Good Manufacturing Practices for human natural health products.

These regulatory changes will be implemented starting in November 2017. Efforts are being made by Health Canada in collaboration with stakeholders to ensure a successful transition to the new rules.

\section{Additional policy initiatives to promote antimicrobial stewardship}

To complement this suite of new regulatory changes, Health Canada has worked over the years, in collaboration with provincial and territorial authorities and other stakeholders, to make additional changes within existing regulatory authorities to promote the responsible use of antimicrobials in animals. This initiative includes two key measures described below.

\section{Making all medically important antimicrobials prescription drugs}

It is anticipated that by December 1, 2018, a prescription will be required from a licensed veterinarian before an individual will be able to purchase a medically important antimicrobial drug for use in animals. Veterinarians, who prescribe for animals under their care, possess the scientific and clinical training to assess the health of animals, diagnose disease conditions, determine the need for antimicrobial drug treatment and choose the most appropriate course of treatment. Consequently, involving veterinarians in making antimicrobial therapeutic decisions is an indispensable component of enhancing antimicrobial stewardship. This is an internationally recognized best practice $(7,13)$. Of note, since 2004, Health Canada has required that all new medically-important antimicrobials (4) for animals be sold pursuant to a prescription by a licensed practitioner. With this change, Health Canada aims to establish the same level of oversight for all medically important antimicrobials sold in Canada, including those approved prior to 2004.

The prescription drug status of in-feed formulations means that a veterinary prescription will be required prior to the sale of medicated feed containing a prescription drug. As per the anticipated policy changes, it is intended that the medicated feed containing a prescription drug can be prepared by a feed mill in advance of receiving a prescription, as long as the feed is made as per the Compendium of Medicating Ingredients Brochure (CMIB). The CMIB is maintained by the Canada Food Inspection Agency (CFIA) (14) and is an important resource for feed mills, veterinarians and producers. It provides instructions on how to manufacture medicated feeds and directions for its use. The CMIB currently includes only non-prescription (over-the-counter) in-feed medications and no drugs with a prescription status are listed. Moving forward, Health Canada and the CFIA intend to include all the approved in-feed drug products, including prescription drugs, in the new version of the CMIB. The prescription will be required prior to the sale of the medicated feed. A prescription will continue to be required prior to the manufacturing of a medicated feed if it is made in a manner not consistent with the CMIB (i.e., in an extra-label manner). The new version of CMIB is anticipated to be launched in spring 2018.

\section{Removing growth promotion claims from medically important antimicrobials}

Specific veterinary antimicrobials were historically authorized for production claims in food animals to promote growth and to improve feed efficiency. This is no longer considered to be a prudent use of such antimicrobials. The decision to remove growth promotion claims from the product labels of medically important antimicrobials is in line with international best practices and principles $(6,13)$. These important drugs should be reserved for treating or preventing diseases and not for enhancing weight gain in animals.

Changes to the drug prescription status and removal of production claims are being implemented concurrently; both require changes to drug labelling. Companies that need to modify labels to identify them as prescription drugs and to remove growth promotion claims will be able to do so simultaneously. Health Canada aims to implement these changes in collaboration with relevant partners including provinces and territories, which have oversight on the distribution and dispensing of these drugs. Implementation is anticipated between February and December 2018 so that there is adequate time to adapt to these changes. Additionally, end users, such as food animal producers, feed mill owners and veterinarians, are being informed of and prepared for these modifications. These changes have required extensive consultation and collaboration among multiple stakeholders over the last several years.

\section{Implications of the new measures}

All regulatory changes and policy measures described above are important and concrete elements of the Government of Canada's Federal Framework and Action Plan on Antimicrobial Resistance and Use $(1,15)$. By the end of the implementation period (expected in late 2018), Canada will have a sound regulatory infrastructure in place at the federal level to further enhance and support antimicrobial stewardship in Canada as summarized in Table 1.

Table 1: Summary of the federal veterinary drug regulatory infrastructure to advance antimicrobial stewardship

\begin{tabular}{|c|c|}
\hline $\begin{array}{l}\text { Type of } \\
\text { infrastructure }\end{array}$ & $\begin{array}{c}\text { How it will advance antimicrobial } \\
\text { stewardship }\end{array}$ \\
\hline \multirow[t]{4}{*}{$\begin{array}{l}\text { New regulatory } \\
\text { provisions }\end{array}$} & $\begin{array}{l}\text { Increased controls over the importation } \\
\text { of medically important antimicrobials for } \\
\text { veterinary use }\end{array}$ \\
\hline & $\begin{array}{l}\text { Increased controls over the quality of active } \\
\text { pharmaceutical ingredients for veterinary use } \\
\text { coming into Canada (aligned with human } \\
\text { drugs) }\end{array}$ \\
\hline & $\begin{array}{l}\text { Increased surveillance of the amount of } \\
\text { medically important antimicrobials for } \\
\text { veterinary use available for sale in Canada }\end{array}$ \\
\hline & $\begin{array}{l}\text { Improved access to veterinary health products, } \\
\text { which are drugs in dosage form that are used } \\
\text { to maintain or promote the health and welfare } \\
\text { of animals and are not for use to treat or cure } \\
\text { disease }\end{array}$ \\
\hline \multirow{2}{*}{$\begin{array}{l}\text { New policies under } \\
\text { existing regulatory } \\
\text { provisions }\end{array}$} & $\begin{array}{l}\text { Making all medically important antimicrobials } \\
\text { prescription drugs }\end{array}$ \\
\hline & $\begin{array}{l}\text { Removing growth promotion claims from labels } \\
\text { of medically important antimicrobials }\end{array}$ \\
\hline
\end{tabular}




\section{Conclusion}

The prudent use of antimicrobial drugs in animals is a shared responsibility across governments, industry and veterinary and agriculture sectors. Health Canada's contributions via the regulatory amendments to the Food and Drug Regulations, as well as other complementary policy initiatives, are essential to ensure safe and effective drug products are on the market and to enhance antimicrobial stewardship in Canada. These efforts will support enhanced understanding of the linkages between antimicrobial use in animals and AMR in animals and humans. It is important that these changes are supplemented and supported by ongoing activities from other partners and stakeholders, including provincial and territorial authorities, veterinarians, pharmaceutical industries and food animal producers, to successfully promote the health and wellbeing of animals and Canadians.

\section{Authors' statement}

$M M, X-Z L-$ writing of original draft, review and editing; MJIwriting, review and editing

\section{Conflict of interest}

None.

\section{Acknowledgements}

The authors would like to thank all those who have been part of this journey and have contributed significantly to these important initiatives to strengthen antimicrobial stewardship in Canada.

\section{References}

1. Government of Canada. Antimicrobial Resistance and Use in Canada: A Federal Framework for Action. Public Health Agency of Canada, Ottawa ON: 2014. https://www. canada.ca/content/dam/canada/health-canada/migration/ healthy-canadians/alt/pdf/drugs-products-medicamentsproduits/buying-using-achat-utilisation/antibiotic-resistanceantibiotique/antimicrobial-framework-cadre-antimicrobienseng.pdf

2. Government of Canada. Tackling Antimicrobial Resistance and Antimicrobial Use: A Pan-Canadian Framework for Action. https://www.canada.ca/en/health-canada/services/ publications/drugs-health-products/tackling-antimicrobialresistance-use-pan-canadian-framework-action.html

3. Health Canada. Guidance for Industry Preparation of Veterinary New Drug Submissions. Ottawa ON: 2007. https://www.canada.ca/en/health-canada/services/drugshealth-products/veterinary-drugs/legislation-guidelines/ guidance-documents/guidance-industry-preparationveterinary-new-drug-submissions-health-canada-2007.html

4. Health Canada. Categorization of Antimicrobial Drugs Based on Importance in Human Medicine. Ottawa ON: 2009. https://www.canada.ca/en/health-canada/services/drugshealth-products/veterinary-drugs/antimicrobial-resistance/ categorization-antimicrobial-drugs-based-importancehuman-medicine.html

5. Health Canada. Uses of Antimicrobials in Food Animals in Canada: Impact on Resistance and Human Health. Advisory Committee on Animal Uses of Antimicrobials and Impact on Resistance and Human Health. Report Prepared for Veterinary Drugs Directorate, Health Canada. Ottawa ON: 2002. https://www.canada.ca/en/health-canada/services/ drugs-health-products/reports-publications/veterinary-drugs/ uses-antimicrobials-food-animals-canada-impact-resistancehuman-health-health-canada-2002.html

6. World Health Organization. WHO Global Strategy for Containment of Antimicrobial Resistance. WHO, Switzerland: 2001. http://www.who.int/drugresistance/WHO_Global_ Strategy_English.pdf

7. World Organisation for Animal Health. OIE International Standards on Antimicrobial Resistance. OIE, Paris, France: 2003. http://www.oie.int/doc/ged/D9769.pdf

8. Office of the Auditor General of Canada. Report 1 Antimicrobial Resistance. Ottawa ON: 2015. http://www.oagbvg.gc.ca/internet/English/parl_oag_201504_01_e_40347. html

9. Government of Canada. Regulations Amending the Food and Drug Regulations (Veterinary Drugs - Antimicrobial Resistance). Canada Gazette Part I 2016;150(27):2357-2405. http://www.gazette.gc.ca/rp-pr/p1/2016/2016-07-02/pdf/g115027.pdf

10. Government of Canada. Regulations Amending the Food and Drug Regulations (Veterinary Drugs - Antimicrobial Resistance). Canada Gazette Part II 2017;151(10):942-999. http://www.gazette.gc.ca/rp-pr/p2/2017/2017-05-17/pdf/g215110.pdf

11. Government of Canada. Antibiotic Resistance and Animals. Ottawa ON: 2017. https://www.canada.ca/en/public-health/ services/antibiotic-antimicrobial-resistance/animals.html

12. Government of Canada. Canadian Integrated Program for Antimicrobial Resistance Surveillance (CIPARS) 2014 Annual Report. Public Health Agency of Canada, Guelph ON: 2016. http://www.phac-aspc.gc.ca/cipars-picra/pubs-eng.php

13. Codex Alimentarius Commission. Code of Practice to Minimize and Contain Antimicrobial Resistance (CAC/ RCP 61-2005). 2005. www.fao.org/input/download/ standards/10213/CXP_061e.pdf

14. Canadian Food Inspection Agency. Compendium of Medicating Ingredient Brochures. Ottawa ON: 2017. http:// www.inspection.gc.ca/animals/feeds/medicating-ingredients/ eng/1300212600464/1320602461227

15. Government of Canada. Federal Action Plan on Antimicrobial Resistance and Use in Canada: Building on the Federal Framework for Action. Public Health Agency of Canada, Ottawa ON: 2015. https://www.canada.ca/content/dam/ canada/health-canada/migration/healthy-canadians/alt/ pdf/publications/drugs-products-medicaments-produits/ antibiotic-resistance-antibiotique/action-plan-daction-eng. pdf 